\title{
Penerapan Healing Architecture dalam Desain Rumah Sakit
}

\author{
Asma, Arinal Haq, dan Erwin Sudarma \\ Jurusan Arsitektur, Fakultas Teknik Sipil dan Perencanaan, Institut Teknologi Sepuluh Nopember \\ (ITS) \\ Jl. Arief Rahman Hakim, Surabaya 60111 \\ E-mail: airwind@arch.its.ac.id
}

\begin{abstract}
Abstrak- Healing architecture secara umum diartikan sebagai penyembuhan yang dilakukan melalui elemen arsitektur. Dalam penerapannya, Healing Architecture umumnya dikaitkan dengan pemberian aspek warna dan alam ke dalam bangunan, mengingat kedua aspek inilah yang terbukti mampu membantu tingkat kesembuhan pasien. Namun secara definisi, penerapan Healing Architecture ini tidak selalu harus diwujudkan dalam bentuk kedua aspek di atas. Pada objek rancang ini, sebuah pendekatan baru diterapkan dalam prinsip Healing Architecture. Pendekatan ini diterapkan dalam objek rancang dengan menghadirkan kehidupan sehari-hari yang disukai sebagian besar masyarakat dalam kegiatan rumah sakit. Perwujudan konsep ini dihadirkan dengan memberikan konsep pusat perbelanjaan (Mall) ke dalam bangunan rumah sakit, sehingga suasana rumah sakit yang dingin dan kaku menjadi lebih hidup dan penuh dengan aktivitas. Pada penerapannya, cakupan rumah sakit dibatasi untuk menampung penyakit kanker dan penyakit yang membutuhkan perawatan paliatif lainnya.
\end{abstract}

Kata Kunci-, Healing Architecture, Mall-like Ambiance, Perawatan Kanker, Perawatan Paliatif, Rumah Sakit.

\section{PENDAHULUAN}

$\mathrm{K}$ ANKER merupakan penyakit yang diperkirakan akan terus bertambah seiring dengan kemajuan jaman. Apalagi didukung dengan perubahan gaya hidup masyarakat yang saat ini lebih mengesampingkan kesehatan ketimbang ekonomi. Diperkirakan, pada tahun 2030 pasien penderita kanker akan mengalami peningkatan sebanyak $300 \%$ di seluruh dunia, dan $70 \%$ penderita berada di negara berkembang seperti Indonesia (Tabel 1). Apabila terus dibiarkan, pertambahan jumlah pasien kanker ini akan menimbulkan angka kematian yang tinggi dan mengurangi harapan hidup masyarakat Indonesia [1] (Gambar 1).

Tabel 1. Statistik Kanker Indonesia tahun 2012

\begin{tabular}{|c|c|}
\hline Population in 2012: & $244.8 \mathrm{~m}$ \\
\hline $\begin{array}{l}\text { People newly diagnosed with } \\
\text { cancer (excluding NMSC) / yr: }\end{array}$ & 299,700 \\
\hline $\begin{array}{r}\text { Age-standardised rate, incidence } \\
\text { per } 100,000 \text { people } / y r \text { : }\end{array}$ & 133.5 \\
\hline $\begin{array}{r}\text { Risk of getting cancer before age } \\
75 \text { : }\end{array}$ & $14.0 \%$ \\
\hline People dying from cancer $/ y r$ : & 194,500 \\
\hline
\end{tabular}

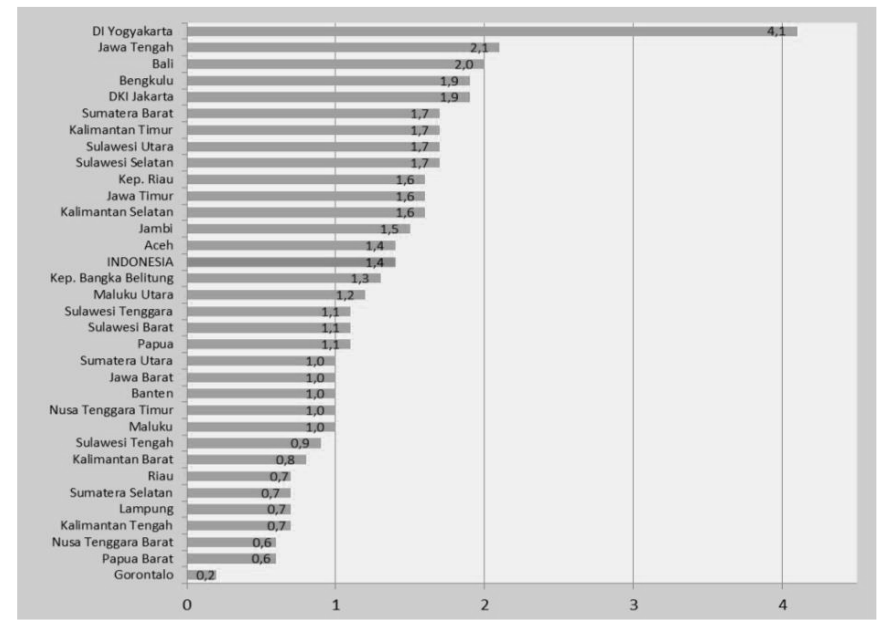

Gambar 1. Prevalensi Kanker pada Penduduk

Dalam menangani kanker, fasilitas diagnosis, pengobatan, terapi, dan pelayanan paliatif akan bergantung besar pada ketersediaan rumah sakit. Namun sayangnya, di Indonesia, pelayanan rumah sakit khusus kanker yang diberikan oleh pemerintah hanya terdapat satu yaitu di Rumah Sakit Kanker Dharmais, sedangkan sisanya ditampung oleh rumah sakit umum dengan fasilitas pelayanan untuk pasien kanker. Hal ini menyebabkan banyaknya penderita kanker yang mendapatkan pelayanan terbatas.

Idealnya, di negara maju, peralatan radioterapi dapat melayani dengan perbandingan 1 alat per 1 juta pasien kanker. Sedangkan di negara berkembang, seperti yang telah diterapkan di India, perbandingan antara alat radioterapi dan pasien adalah 1 alat per 2,5 juta pasien. Jumlah ini masih jauh apabila dibandingkan dengan Indonesia yang hanya memiliki perbandingan 1 alat per 4 juta pasien. Akibatnya, dari seluruh rumah sakit dan fasilitas peralatan radioterapi yang ada, pasien kanker yang terlayani dengan baik hanya mencangkup sekitar $15 \%$ dari seluruh penderita kanker di Indonesia [2] (Gambar 2).

Di sisi lain, pelayanan aspek lain bagi penderita kanker juga banyak yang dikesampingkan. Dalam perancangan rumah sakit dan pelayanan terhadap pasien aspek yang paling diutamakan adalah perawatan fisik pasien. Aspek 


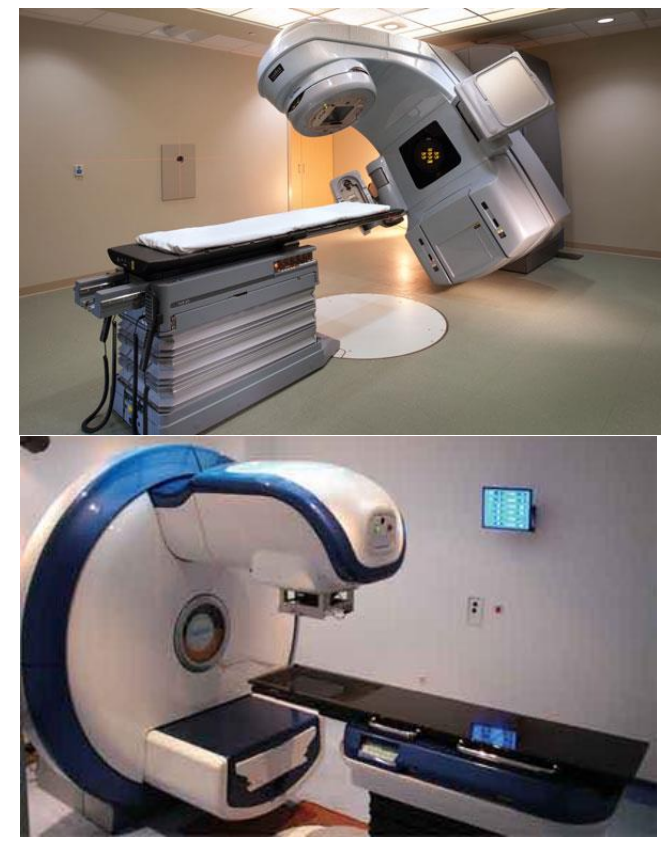

Gambar 2. Alat LINAC (atas) dan Cobalt-60 (bawah)

psikologi, sosial, apalagi spiritual, jarang sekali tersentuh dan terpikirkan dalam perancangan.

Penderita kanker cenderung untuk merasa malu atau takut untuk membicarakan penyakit yang dideritanya, termasuk pada keluarga dan civitas medis yang melayani. Pada akhirnya, pasien sering menarik diri dari interaksi dan kontak sosial akibat perasaan berbeda dari penyakit yang dideritanya [3].

Dari penjelasan di atas, dapat ditarik sebuah kesimpulan permasalahan yaitu kurang tepatnya desain rumah sakit bagi penderita kanker yang ada selama ini. Penyakit kanker merupakan penyakit yang berbeda dengan penyakit lain, karena tingkat kematiannya yang tinggi dan menyebabkan tingkat kecemasan yang tinggi pada pasien dan keluarganya. Pada akhirnya, pasien atau keluarganya akan berusaha mencari pengobatan yang terbaik, hingga terkadang melupakan pengobatan konvensional yang seharusnya tetap dilakukan.

Dari permasalahan tersebut maka rancangan yang diperlukan adalah rumah sakit yang menyediakan berbagai pelayanan-pelayanan teruji dan terpercaya, sehingga pasien dapat bebas untuk memilih perawatan lebih bagi penyakitnya atau meningkatkan kualitas hidupnya. Selain itu, untuk menciptakan lingkungan penyembuhan yang optimal bagi pasien, dibutuhkan desain yang mempertimbangkan seluruh aspek fisik, psikologis, sosial, dan spiritual penggunanya. Sehingga desain yang diperlukan, tidak hanya terfokus pada penyediaan fasilitas saja, namun juga bagaimana peningkatan kondisi psikologis pengguna di dalamnya.

\section{PROGRAM RANCANG}

\section{A. Deskripsi Lahan}

Lahan (Gambar 3) berada di jalan Raya Lontar, Komplek Villa Bukit Regency, kelurahan Babatan, kecamatan

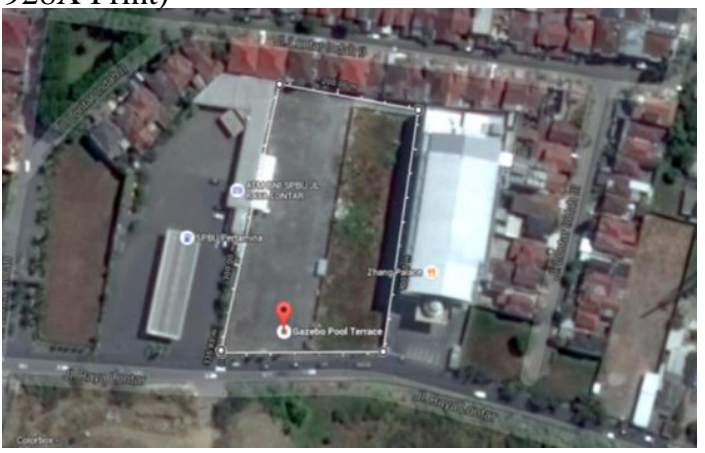

Gambar 3. Citra Satelit Lahan

Wiyung, Surabaya Barat. Luas total dari lahan ini adalah $7.236 \mathrm{~m}^{2}$. Lahan terletak di antara daerah sibuk perdagangan (mall, area bisnis dan ruko) dan pemukiman. Pemukiman di sekitarnya juga beragam dari menengah ke atas (apartemen), menengah (perumahan), hingga daerah menengah ke bawah (kampung) [4].

\section{B. Fasilitas}

Fasilitas pada bangunan dibedakan menjadi enam kelompok besar yaitu pelayanan medik, pengobatan komplementer, penunjang medik, pengelolaan, fasilitas umum, dan servis (Gambar 4). Pelayanan medik merupakan unit yang berhubungan dengan pemberian pelayanan secara medis secara langsung pada pasien. Pengobatan Komplementer merupakan unit yang menyediakan pengobatan bersifat komplementer pada pasien. Karena sifat dan sistem penangannya yang berbeda dengan pelayanan medik biasa, unit ini dipisahkan dari unit pelayanan medik.

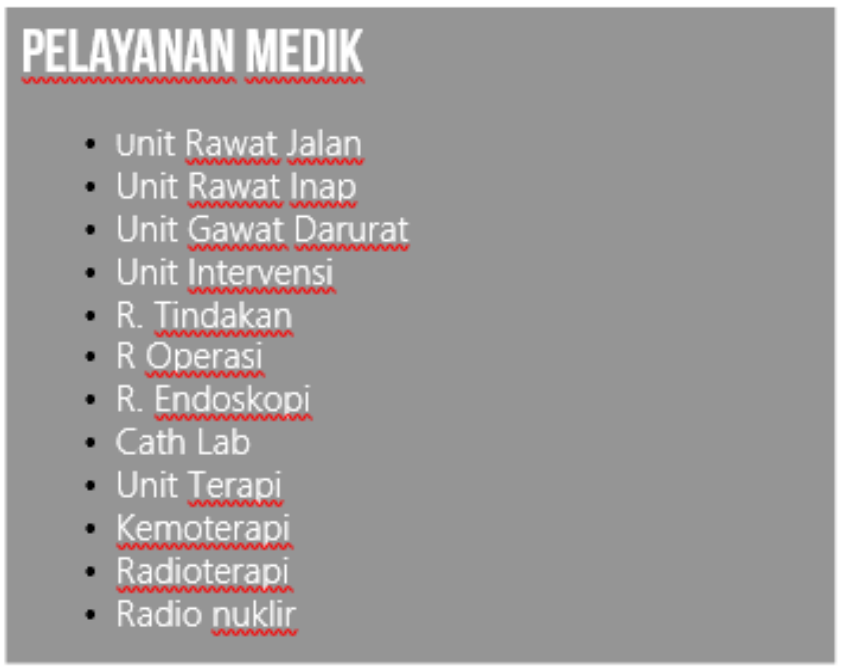

PENUNUANG MEDIK

- Unit Farmasi

- Unit Radio diagnostik

- Unit Laboratoriun

Gambar 4. Outline fasilitas dalam Rumah (a). 

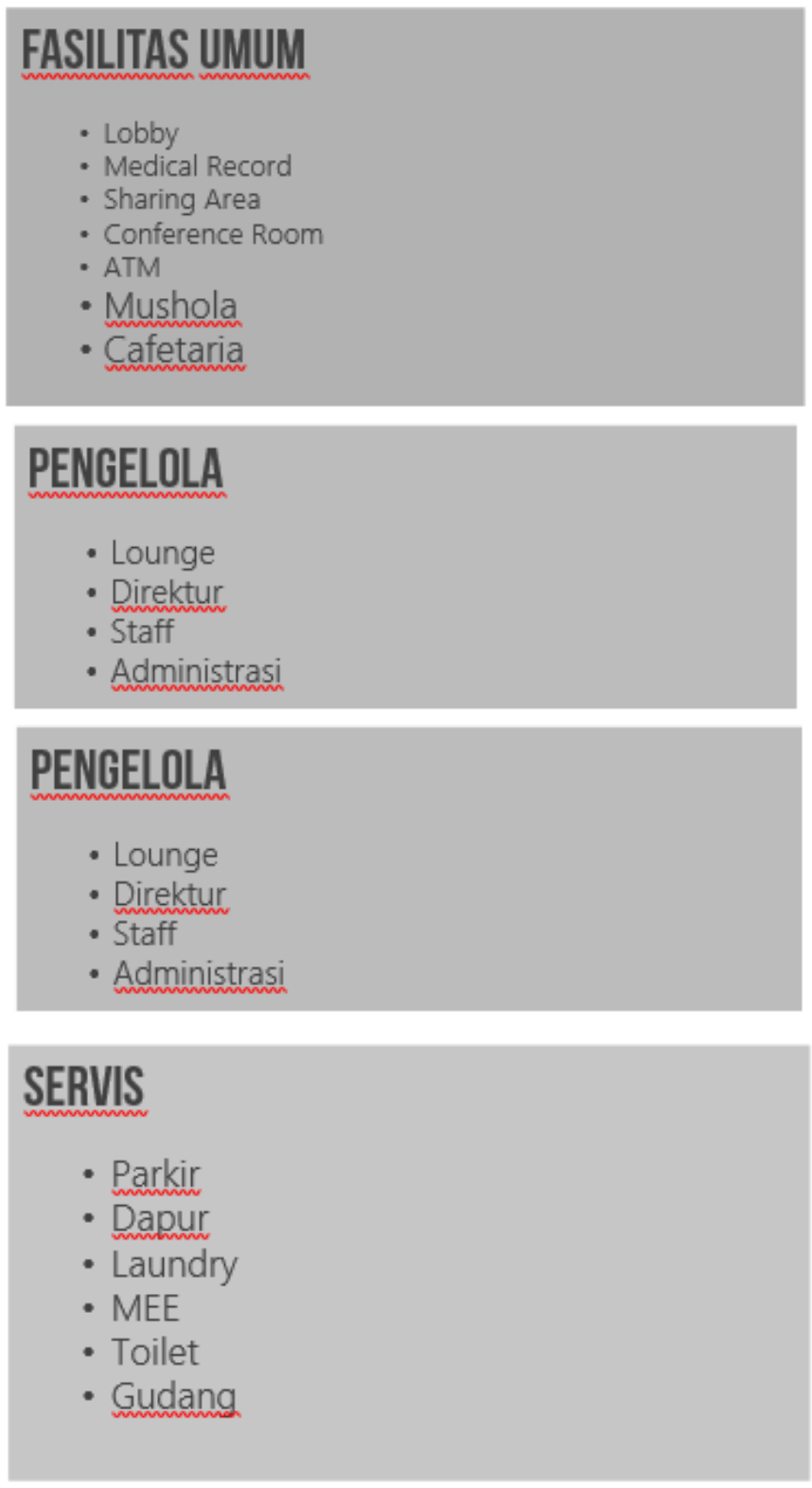

Gambar 4. Outline fasilitas dalam Rumah (b).

Penunjang medik merupakan unit yang berhubungan dengan aktivitas yang menunjang bagian pelayanan medik. Pengelolaan merupakan bagian yang menjadi fasilitas bagi pengelola dalam menjaga keberlangsungan sistem dan operasional dalam bangunan. Fasilitas umum merupakan unit yang menyediakan berbagai fasilitas yang menunjang kenyamanan pengguna dalam bangunan. Servis merupakan bagian yang berhubungan dengan sistem kerja bangunan.

\section{PENDEKATAN DAN METODE DESAIN}

Pendekatan desain yang dilakukan adalah dengan healing architecture. Healing architecture merupakan pendekatan yang dilakukan demi menciptakan bentuk dan lingkungan arsitektur yang mendukung kesembuhan pasien. Dalam menciptakan lingkungan arsitektur yang optimal demi kesembuhan pasien, terdapat tiga aspek yang perlu menjadi perhatian utama dalam desain yaitu people, process, dan Place [5] (Gambar 5).

Metode desain yang digunakan adalah Evidance-based Design (EBD). EBD merupakan metode desain yang menekankan pada penggunaan bukti dan sumber yang nyata pada desain. Pada proses metode EBD, terdapat empat langkah utama yang dilakukan yaitu riset, analisis, implementasi, dan evaluasi [6] (Gambar 6).

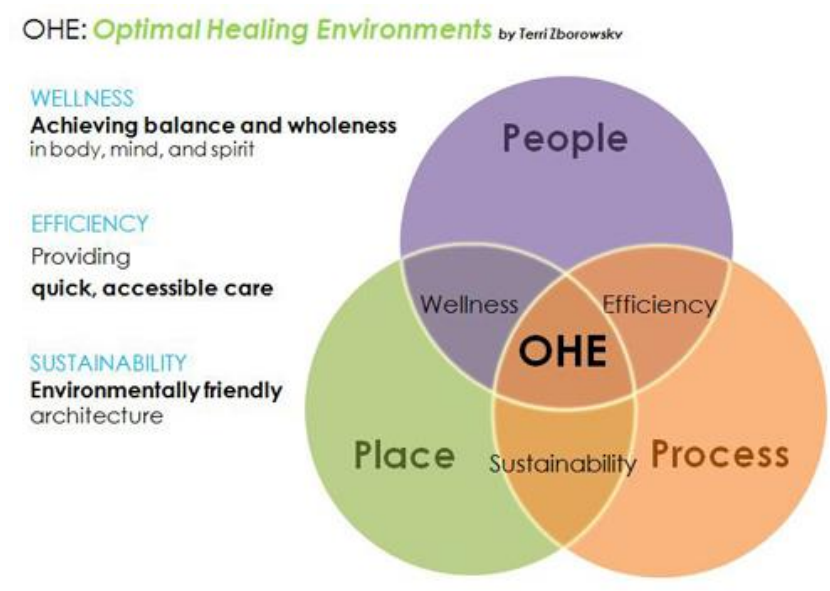

Gambar 5. Optimal Healing Evironmet

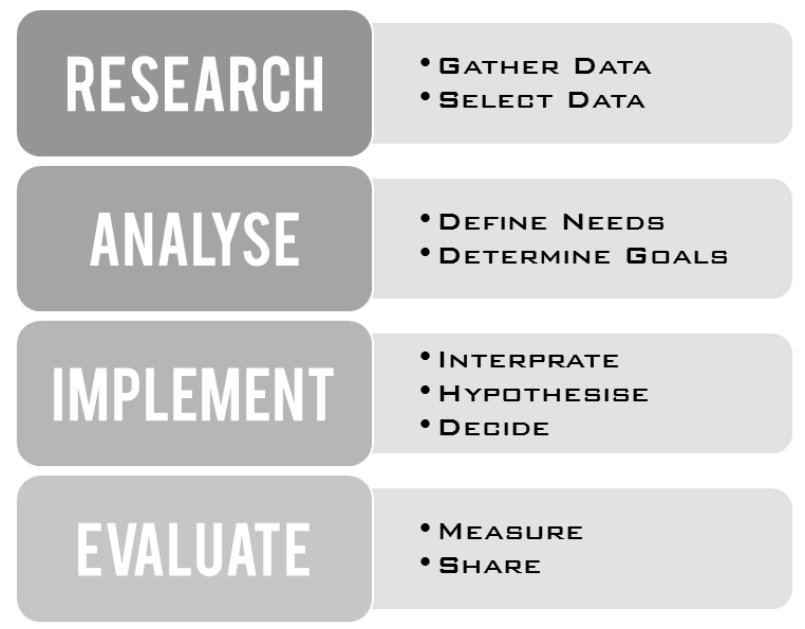

Gambar 6. Proses Evidence Based Design

Pada tahap riset dilakukan pengumpulan data mengenai standar-standar rumah sakit dan persyaratannya [7][8] serta mengenai pendekatan dan definisi dari healing architecture itu sendiri [9].

Pada tahap analisis dilakukan pendalaman terhadap prinsip healing architecture. Healing Architecture di sini diartikan sebagai penyembuhan terhadap pengguna melalui elemen-elemen arsitektur. Pemberian penyembuhan ini dihadirkan dengan memberikan suasana kehidupan penuh aktivitas orang sehat pada umumnya, sehingga pasientidak merasa terasingkan dari kehidupan normal dunia sehari-hari. Aktivitas yang dipilih dalam desain ini adalah aktivitas 
dalam mall. Aktivitas dalam mall dianggap paling sesuai untuk dimasukkan ke dalam rumah sakit karena aktivitas dalam mall, yaitu proses belanja, sering dianggap sebagai aktivitas hiburan bagi masyarakat Surabaya. Selain itu, suasana mall yang terasa bersih dan teratur dapat sesuai dengan suasana rumah sakit yang steril.

Pada tahap implementasi, suasana mall ini diberikan dengan memberikan void dengan pencahayaan alami matahari yang terbuka pada bagian tengah bangunan. Dalam void ini diletakkan jembatan yang berbeda bentuknya di setiap lantai (Gambar 6). Hal ini dilakukan agar memberi bentukan yang tidak kaku dan menambah kesan hidup yang lebih dalam rumah sakit. Pada jembatan ini diletakkan cafecafe sehingga aktivitas pada area ini menjadi hidup dan menjadi area sosial yang efektif untuk melupakan rasa sakit pengguna.

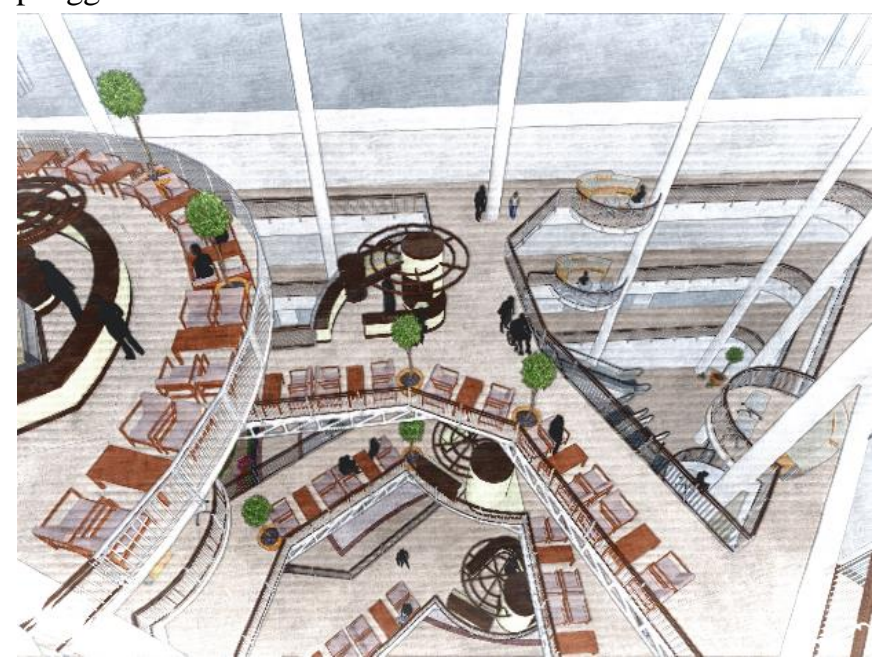

Gambar 7. Jembatan dan cafe di tengah bangunan

\section{EKSPLORASI DAN HASIL RANCANG}

Penerapan healing architecture dalam juga diwujudkan dalam bentuk lain. Pasien yang membutuhkan perawatan paliatif membutuhkan dukungan sosial yang lebih dibanding pasien pada umumnya. Hal ini dikarenakan proses perawatan yang cenderung lama dan hasilnya tidak cepat terlihat. Oleh karena itu, rumah sakit bagi pasien kanker dan paliatif perlu memberikan fasilitas bagi pasien dan pengguna lainnya untuk bersosialisasi dan berbagi perasaan saling mendukung.

Dengan adanya area jembatan ini, timbul area-area sosial di setiap lantai yang menjadi titik pusat perhatian dan aktivitas. Selain pada area jembatan silang yang berada di tengah, juga tetap perlu diberikan area-area sosial lain yang nyaman dan memiliki tingkat privasi yang sedikit lebih tinggi, namun tetap berada di area yang terbuka. Area ini diletakkan di setiap lantai pada bangunan. Untuk menambah privasi, area ini diletakkan pada pojok bangunan sehingga tidak mudah terganggu oleh aktivitas dalam rumah sakit. Selain itu, pada area ini, pengguna dapat menikmati pemandangan di luar bangunan, dan memberikan kesan yang berbeda dari pemandangan mall di bagian tengah bangunan.
Pada area inap, yang pada umumnya banyak dikunjungi keluarga dan pendamping pasien lainnya, area sosial diperbanyak sebagai respons dari banyaknya aktivitas sosial yang lebih intens terjadi di area ini (Gambar 7).

Elemen alam juga diberikan dengan memberikan area taman yang memenuhi satu fasad dinding pada area-area yang mampu memberikan tingkat stress yang tinggi dan terkesan menyeramkan bagi pasien. Area-area ini adalah area diagnosis radiologi, area treatment medis ruang LINAC dan kemoterapi. Area taman ini batasi oleh kaca sehingga kesan steril tetap dapat dicapai dalam rumah sakit (Gambar 9).

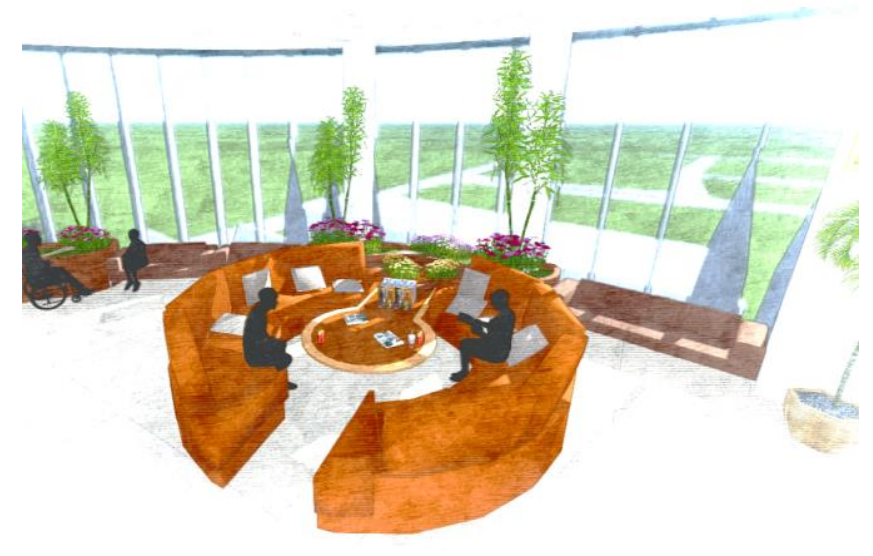

Gambar 8. Area sosial

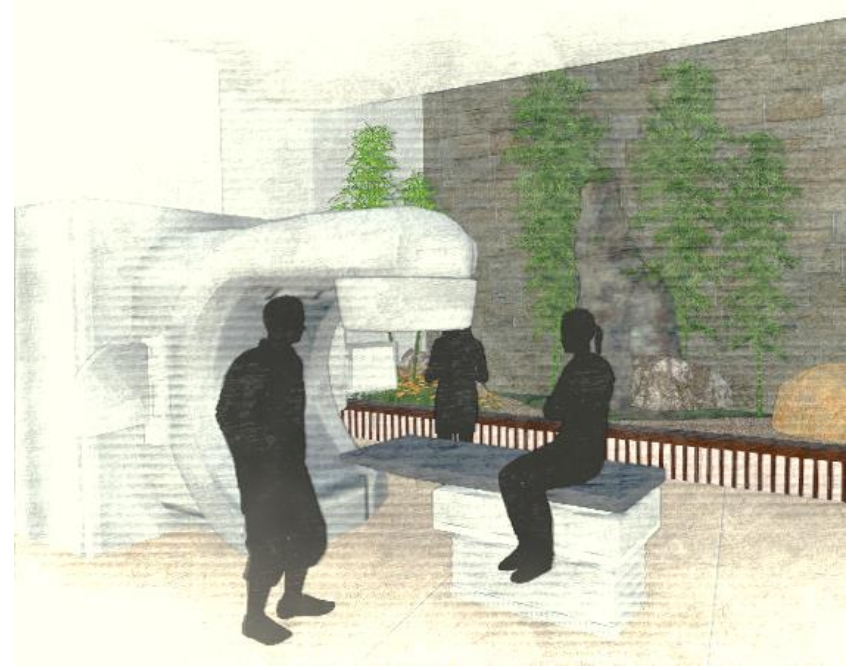

Gambar 8. Taman dalam ruang LINAC

Struktur utama bangunan merupakan sistem struktur rangka. Pada bagian perimeter bangunan bahan yang digunakan pada sistem rangka adalah baja komposit. Pada bagian jembatan dan penopang atap tengah digunakan sistem truss dengan pipa baja (Gambar 10). Prinsip struktur ini dipilih agar kesan bebas mall yang ada semakin kuat. Selain itu, prinsip struktur dan preseden yang digunakan mengambil dari struktur salah satu mall di Surabaya, yaitu Galaxy Mall, sehingga pengguna pun dapat merasa teringat dengan kesan mall. 


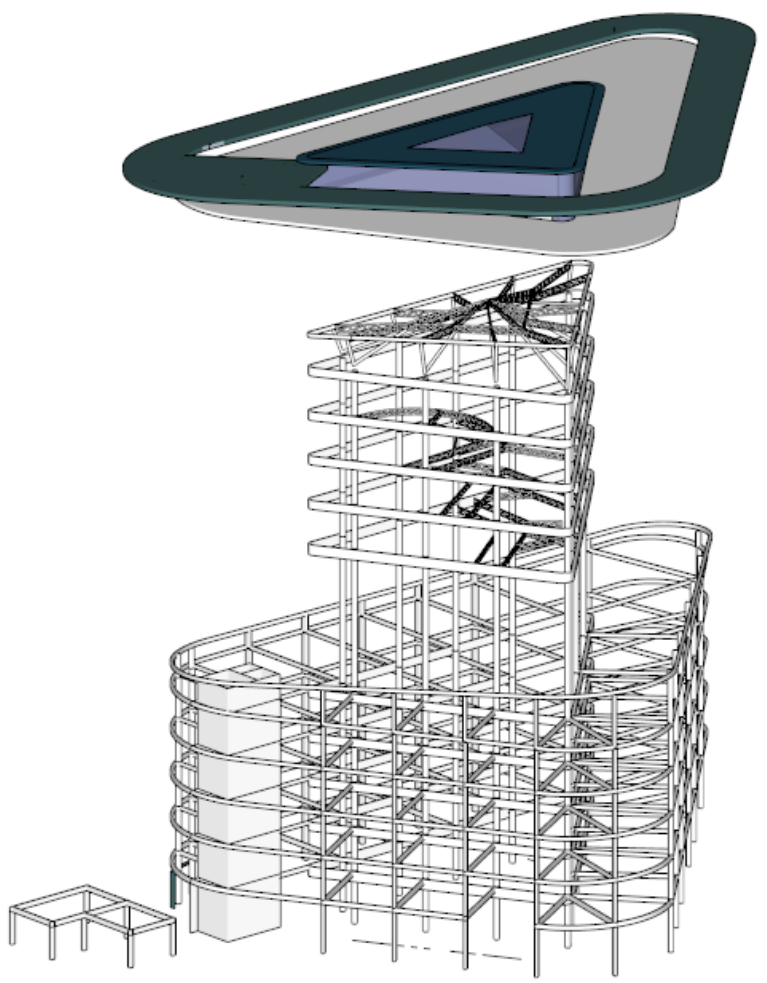

Gambar 10. Prinsip struktur bangunan

Jalur air bersih dan listrik tetap diberikan untuk area cafe di area jembatan melalui area di bawah lantai, sehingga pengguna cafe tetap dapat mendapatkan sarana air dengan mudah.

\section{KESIMPULAN}

Pendekatan healing architecture dapat dilakukan tidak harus dengan menerapkan elemen warna dan atau alam ke dalam bangunan. Healing architecture dapat dicapai dengan memberikan suasana yang membuat pengguna melupakan rasa sakitnya, misalnya dengan memasukkan suasana yang penuh aktivitas kehidupan ke dalam bangunan.

\section{DAFTAR PUSTAKA}

[1] Manajemen Rumah Sakit, "Prevelensi Kanker di Indonesia dan Dunia", Diakses pada: http://manajemenrumahsakit.net/2014/01/prevalensi-kanker-diindonesia-dan-dunia/.

[2] Penyakit Kanker, "Statistik Penderita Kanker di Indonesia", Diakses pada: https://www.deherba.com/statistik-penderita-kanker-diindonesia.html.

[3] Ratna, J., "Dampak Penyakit Kanker Terhadap Aspek PsikologisSosial dan Spiritual Penderita", Diakses pada: http://josephineratna.blogspot.co.id/2003/12/dampak-penyakit-kanker-terhadapaspek.html.

[4] Kantor Dinas PU Cipta Karya dan Tata Ruang-Pemerintah Kota Surabaya, Peta Peruntukan Surabaya, diakses pada http://petaperuntukan.surabaya.go.id/cktr-map/

[5] R. Coles," "Architecture Students Explore Healing Healthcare Design", Diakses pada: http://blog.lpainc.com/lpablog/bid/53151/Architecture-Students-Explore-Healing-HealthcareDesign.
[6] Health Facilities Scotland (2011), Research Report: Evidence Based Design, National Service Scotland, Scotland.

[7] Ernst na P. Neufert, Data Arsitek, Jakarta: Erlangga (1996).

[8] S. A. Kliment, R. L. Kobus, R. L. Skaggs, M, Bobrow, J. Thomas, dan T. M. Payette Building Type Basics for Healthcare Facilities, New York: John Wiley \& Sons Inc. (2000).

[9] B. Lawson, "Healing architecture", Arts \& Health, Vol. 2, No. 2, (2010) 95-108 